\title{
Teaching professionalism and ethical reasoning to pharmacy students: How important it is?
}

\author{
Rana M Ibrahim* and Suleiman I Sharif \\ Department of Pharmacy Practice \& Pharmacotherapeutics, College of Pharmacy, University of Sharjah- UAE
}

Pharmacy schools around the globe aim to graduate appropriately trained professional pharmacists with the skills and ability to provide patient-focused care. These schools aim to produce moral pharmacists who are compassionate and have the ability to put their patient's interests above their self-interest. Training in ethical reasoning is important for pharmacy students because students at greater levels of moral development may show a bigger likelihood of following a higher level of patient focused care. As pharmacy moves closer to the patientoriented care model, opportunities for complex ethical dilemmas will increase [1]. When chores are inconsistent, as is frequently the occasion in providing pharmaceutical care, people at lower levels of ethical reasoning may have poorer conceptual tools when tackling a social or ethical dilemma [2].

An important reason why ethical reasoning is important in pharmacy education is that educational interventions in pharmacy colleges may improve student ethical development. Peer discussion of ethical dilemmas may nurture ethical and moral development as shown in previous studies [3]. Discussing dilemmas exposes students to ethical problem solving and gives them a chance to value their peers higher levels of ethical arguments. Based on a study in pharmacy education, it was concluded that ethical reasoning skills are both teachable and computable and that ethical dilemma discussion can enhance ethical improvement [4]. Another important reason why ethical development is important to pharmacy education relates to its significant association with clinical performance. Various studies in pharmacy, medicine, nursing, and physical therapy demonstrated that individuals at higher levels of ethical development seem inclined to behave in a more professional fashion regarding clinical decision making [5]. Furthermore, practicing ethical dilemma discussions as part of the ethics and law course throughout pharmacy curricula, will lead pharmacy students to behave in a professional mode when exposed to ethical dilemmas in their future work environment.

Different tools have been used to evaluate an individual's level of ethical or moral development. Examples of these tools are the Moral Judgement Interview (MJI) and the Defining Issues Test (DIT). In

Copyright: (C2018 Ibrahim RM. This is an open-access article distributed under the terms of the Creative Commons Attribution License, which permits unrestricted use, distribution, and reproduction in any medium, provided the original author and source are credited. the College of Pharmacy at the University of Sharjah, the Law and Ethics course is taught to fourth year students every spring semester. In addition to the law, students are introduced to Good Pharmacy Practice (GPP) standards; ethical principles, professional code of ethics, code of conduct, rules pertaining to the scope of practice of pharmacy personnel, the duty to do good and avoid harm, privacy and confidentiality, principle of autonomy, rule of informed consent, principle of veracity, paternalism, principles of avoidance of killing and other crucial concepts that help students develop a strong ethical backbone to help them carry on and make better decisions when faced with real life future challenging ethical predicaments.

Studies have identified pertinent elements to professionalism, such as reliability and dependability, taking accountability for one's learning, behaving ethically, communicating respectfully and coherently, struggling to high standards and exceeding expectations, and putting other's needs above one's own [6]. Professionalism is learnt, experienced and facilitated in the academic atmosphere of pharmacy. Another aspect of professionalism is achieved through practice experience in the final year of pharmacy program where students are exposed to different practice sites and various preceptors or role models. Learnt professionalism, attitudes and behavior are indeed transmitted into the workplace, and how they are and how they can be further developed, will have to be more explored in the future.

\section{References}

1. Haddad AM (1991) Ethical problems in pharmacy practice. Am J Pharm Educ 50: 1-6.

2. Rest JR (1994) Background: Theory and Research, In: Narvaez, D. and Rest, J.R., eds, Moral development in the profession: Psychology and Applied Ethics, Lawrence Erlbaum Associates, Hillsdale, NJ.

3. Penn WY (1990) Teaching ethics-A direct approach. J Moral Educ 19: 124-138.

4. Latif DA (2000) The relationship between ethical dilemma discussion and moral development. Am J Pharm Educ 126-133.

5. Sheehan TJ, Husted SD, Candee D, Cook CD, Bargen M (1980) Moral judgment as a predictor of clinical performance. Evaluat Health Prof 8: 379-400.

6. Hammer DP, Berger BA, Beardsley RS, Easton MR (2003) Student professionalism. Am J Pharm Educ 67: 96.
*Correspondence to: Rana Ibrahim, PharmD, Pharmacy Practice/Clinical Pharmacy Lecturer, Dept. Pharmacy Practice \& Pharmacotherapeutics, College of Pharmacy, University of Sharjah, UAE, E-mail: ribrahim@sharjah.ac.ae

Received: October 29, 2018; Accepted: October 30, 2018; Published: October 31,2018 